\title{
Sustainability transitions to low-carbon societies: insights from European community-based initiatives
}

\author{
Filippo Celata ${ }^{1}$ Liz Dinnie ${ }^{2} \cdot$ Anne Holsten $^{3}$
}

Received: 5 March 2019 / Accepted: 13 March 2019 / Published online: 25 March 2019

(C) Springer-Verlag GmbH Germany, part of Springer Nature 2019

\section{Introduction}

This special issue presents one of the first systematic, comparative, and multi-dimensional assessments of the contribution of "community-based" or grassroots initiatives to a transition towards a low-carbon society. The papers characterize and quantify the impact of activities across many different domains of community engagement, such as community gardens, solidarity purchasing groups, community-supported agriculture, alternative food networks, recycling, sustainable mobility, and renewable energy. The special issue is grounded within the emerging body of research around socio-technical transitions (Makard et al. 2012), grassroots innovations (Seyfang and Smith 2007), and the impacts of transition initiatives (Feola and Nunes 2014). The idea is that complex sustainability challenges underlying regional environmental change can only be addressed through a combination of technological, institutional or macro-scale changes and policies, and a more grounded and bottom-up evolution of societal practices and behaviors (Shove 2010). In this, the contribution of grassroots experiments and the possibility of "communityled" sustainability transitions is capturing increasing interest (Middlemiss and Parrish 2010; Seyfang and Smith 2007; Smith and Seyfang 2013). This renewed interest is also due

\section{Filippo Celata}

filippo.celata@uniroma1.it

Liz Dinnie

liz.dinnie@hutton.ac.uk

Anne Holsten

holsten@pik-potsdam.de

1 Department MEMOTEF, University of Rome La Sapienza, Via del Castro Laurenziano 9, 00161 Rome, Italy

2 James Hutton Institute, Social, Economic and Geographical Sciences, Aberdeen, Scotland AB15 8QH, UK

3 Potsdam Institute for Climate Impact Research (PIK), Telegraphenberg A 31, 14473 Potsdam, Germany to dissatisfaction with the outcome of international and national agreements to address climate change, and encompasses the idea that local and citizen-led initiatives can make a significant contribution to reductions in environmental impacts by embodying and promoting voluntary, locally-led solutions, while encouraging wider changes and demonstrating that a bottom-up and community-based transition towards sustainability is possible.

This capacity of community-based sustainability initiatives (CBIs) has been rarely the object of comprehensive empirical assessment. Most of the existing research focuses on specific community experiments, if not on single case studies, with interesting results that however cannot be easily generalized (for a review see Sengers et al. 2016). More comprehensive analysis of, for example, transition initiatives has been attempted; but insofar as transition initiatives may be either community-led or government-led and sometimes even private initiatives, the specificity of CBIs is not always distinguishable. Moreover, research in this field sometimes merely aims to provide a taxonomy of the characteristics of initiatives, rather than an assessment of their impacts (Castán Broto and Bulkeley 2013; Ehnert et al. 2018; Mattijssen et al. 2018), or is based on an analysis of the motivations behind an individual's engagement with CBIs, rather than of their outcomes (Axon 2016; Byrne et al. 2017). A wealth of both case study-based research and more comprehensive assessments has been produced, but with regard to specific domains of grassroots initiatives (Middlemiss 2011; Seyfang and Longhurst 2016), for example community energy (see for example Seyfang et al. 2013 , 2014). Energy is, however, only one of various domains of active citizenship and community engagement that, in this special issue, will be assessed comparatively. More systematic, multi-dimensional, and multi-domain assessments have been proposed (Forrest and Wiek 2014; Hobson et al. 2016; Luederitz et al. 2017), but not implemented, or applied only to a very limited number of initiatives (Forrest and Wiek 2015; Schapke et al. 2017).

A main aim of this special issue is therefore to fill this research gap by assessing a large set of CBIs engaged in a variety of activities, in their capacity to produce an impact 
across several environmental and socio-economic dimensions, with a particular focus on climate change mitigation. The articles present results of the European research project TESS (Towards European Societal Sustainability) under which a comparative assessment of 63 CBIs was carried out across six European countries (Germany, Scotland, Spain, Italy, Finland, and Romania) and which are engaged in the domains of transport, energy, food, and waste (www.tesstransition.eu). For this purpose, CBIs have been identified from the ground up, using an inductive approach, in order to obtain the most varied and exhaustive sample, while previous research focused often upon initiatives adhering to a specific network and used network members to assess impacts (Feola and Nunes 2014; Hobson et al. 2016).

We propose novel methods to assess CBIs that have been designed to both respond to our specific research questions, and provide to the scientific community a flexible approach that can be applied to a wide range of typologies of initiatives, domains of activity, or geographical contexts. We are aware that to apply the same methods to the analysis of such a variety of initiatives is challenging, but we are confident that our analyses provide robust results that, we hope, can inform future research in this field and promote an evidence-based approach to the topic. To this end, the research brought together a broad range of different kinds of expertise, from both the natural and social sciences. In line with the wide scope of the transition research, the papers present several approaches for monitoring and evaluating the environmental, social, political, and economic impacts of CBIs. The aim is also to provide a deeper understanding of the diverse characteristics and capacities of initiatives, shed further light on their development trajectories, and reflect upon the potentialities as well as the challenges of a community-led sustainability transition. Besides being aimed at advancing the state of the art of research in this field, this collection aims as well to analyze the tangible contribution of CBIs to sustainability in Europe and beyond, relevant also for policy-makers and key stakeholders.

Read individually, the papers here offer insights into particular features of low-carbon community initiatives; together, they explore in greater detail than has been previously attempted, the role of CBIs in societal transitions to sustainable and low-carbon societies, their potential for diffusion and up-scaling, as well as the barriers they face, and how to overcome those.

\section{Contents and themes}

The collection of papers in this issue explores a broad range of characteristics, evolutionary dynamics, and impacts of community-based sustainability initiatives.

A necessary pre-requisite to our grounded approach to the topic is to carefully identify the case study initiatives to be selected for further assessment. A sampling strategy is presented in the first article (Tikkanen et al. 2019), together with a discussion of the main challenge in this regard: the diverse characteristics of CBIs, and how to methodologically cope with such diversity in the selection of a sample of initiatives conducting several activities in six different countries. Building on previous methodologies for selecting case studies, the paper describes the process through which a multicriteria cognitive mapping and preference analysis was used with a multi-disciplinary research team and stakeholders to justify the selection of case studies. The paper further discusses how the process revealed different preferences between the research team and how these were included in the final selection. This process could be applied in similar projects where case study selection criteria need to be established across a diverse population and between a multi-disciplinary team.

A key focus of the research project has been on CBIs' contribution to reduce carbon emissions which has never been attempted in a systematic manner across a variety of activities so far. Landholm et al. (2018) therefore assess the greenhouse gas (GHG) emissions of the selected CBIs, in order to quantify and compare their reduction potential. This is another complicated task due, in large part, to the diversity of activities undertaken through community engagement. To achieve this, a minimum set of input data from CBIs is identified and a new methodological framework is presented for a set of common activities they are engaged in within the food, energy, waste, and transport domains. Results show that CBIs that promote the use of renewable energy, sustainable mobility solutions, and dietary changes, can provide a significant reduction of the carbon footprint of beneficiaries, while the impacts of other forms of community engagement are more limited in terms of GHG emissions, but can be relevant in terms of community resilience and social cohesion.

The third article aims to widen the scope of the previous assessment, by considering the environmental impacts of CBIs alongside their capacity to promote social capital, inclusion, human capital, economic revitalization, financial sustainability, and innovation (Celata and Sanna 2019). The article applies a multi-criteria assessment framework and shows that those typologies with the highest environmental and economic impacts - community energy and to a lesser extent mobility initiatives - are weaker in terms of social capital and inclusion, relative to other typologies that perform strongly in this regard, in particular community gardens. However, the article shows that initiatives can have substantial impacts even if their typology performs weakly, and that diversification of activities is an asset: the specific activities undertaken are therefore less important than how they are conducted, and the possibility of a community-led transition rests on the capacity to promote changes across several dimensions combined. 
In the next article (Martellozzo et al. 2019), the focus of assessing the environmental impacts of community-based initiatives switches to their potential to contribute to climate change mitigation at a broader scale. The authors take a systematic approach to assess what would happen if the activities of CBIs could be appropriately scaled up, what the implications would be for societal engagement in sustainable activities, and the effects this could have on meeting national and international climate change mitigation targets such as those set by the EU strategy for 2020 and 2030. Results show that, although varying greatly among countries, CBIs' contribution to reach GHG reduction targets can be important, but requires a substantial societal engagement in the activities of those initiatives.

The following article (Revell and Henderson 2018) develops a tool for understanding the contribution of diverse CBIs to building community resilience. The "Resilience Compass" tool developed in the paper aims to help decision-makers in thinking about how best to support different community activities, as well as providing a practical way for community groups to self-assess their own performances, think about their priorities, and set goals and targets to help them move in the direction they would like to go. Resilience is therefore operationalized not as a way to react to external shocks, but to proactively seek ways to adapt to change that are empowering for communities.

The sixth and final paper considers potential problems and challenges in the relationship between CBIs, policies, and politics (Celata and Coletti 2019). Although CBIs are fully autonomous, public policies can be crucial in favoring or disfavoring their emergence, development, and diffusion. The article adopts an empirical approach to explore the variety of political or apolitical, collaborative or confrontational attitudes of initiatives, as well as the most recurrent obstacles or support that public institutions and other political stakeholders provide, and the influence of the context in this regard. On this basis, and as a conclusion for the whole special issue, the article identifies some of the most important areas where public policies can make a difference in facilitating or hindering a community-led sustainability transition, and provides several policy recommendations.

In conclusion, we think this special issue brings a novel inquiry and systematic research approach to a growing phenomenon that, despite some exceptions, has previously relied on anecdotal evidence or lack of systematic frameworks. In bringing these papers together, however, we do not suggest that this is the final inquiry into the impact of CBIs, but rather an intermediate step which aims to provide some preliminary evidence and provoke further debates on the role of grassroots activity in societal transition towards a more sustainable society and economy. Many other questions are still to be answered about how initiatives scale-up their activities, how multiple impacts are identified and compared, and how policy environments are or may be designed to promote a deeper and wider community-led transition.
Funding information The research received the financial support of the European Union Seventh Framework Programme FP7/2007-2013 under grant agreement no. 603705 .

\section{Compliance with ethical standards}

Disclaimer The European Commission is not liable for any use that can be made of the information contained herein.

\section{References}

Axon S (2016) "The good life": engaging the public with communitybased carbon reduction strategies. Environ Sci Pol 66:82-92. https:// doi.org/10.1016/j.envsci.2016.08.007

Byrne R, Byrne S, Ryan R, O'Regan B (2017) Applying the Q-method to identify primary motivation factors and barriers to communities in achieving decarbonisation goals. Energy Policy 110:40-50. https:// doi.org/10.1016/j.enpol.2017.08.007

Castán Broto V, Bulkeley H (2013) A survey of urban climate change experiments in 100 cities. Glob Environ Chang 23:92-102. https:// doi.org/10.1016/j.gloenvcha.2012.07.005

Celata F, Coletti R (2019) Enabling and disabling policy environments for community-led sustainability transitions. Reg Environ Chang. https://doi.org/10.1007/s10113-019-01471-1

Celata F, Sanna VS (2019) A multi-dimensional assessment of the environmental and socioeconomic performance of community-based initiatives in Europe. Reg Environ Chang. https://doi.org/10.1007/ s10113-019-01493-9

Ehnert F, Frantzeskaki N, Barnes J, Borgström S, Gorissen L, Kern F, Strenchock L, Egermann M (2018) The acceleration of urban sustainability transitions: a comparison of Brighton, Budapest, Dresden, Genk, and Stockholm. Sustainability 10:612. https://doi. org/10.3390/su10030612

Feola G, Nunes R (2014) Success and failure of grassroots innovations for addressing climate change: the case of the transition movement. Glob Environ Chang 24:232-250. https://doi.org/10.1016/j. gloenvcha.2013.11.011

Forrest N, Wiek A (2014) Learning from success - toward evidenceinformed sustainability transitions in communities. Environ Innov Soc Trans 12:66-88. https://doi.org/10.1016/j.eist.2014.01.003

Forrest N, Wiek A (2015) Success factors and strategies for sustainability transitions of small-scale communities-evidence from a cross-case analysis. Environ Innov Soc Trans 17:22-40. https://doi.org/10. 1016/j.eist.2015.05.005

Hobson K, Hamilton J, Mayne R (2016) Monitoring and evaluation in UK low-carbon community groups: benefits, barriers and the politics of the local. Local Environ 21:124-136. https://doi.org/10.1080/ 13549839.2014.928814

Landholm DM, Landholm HA, Martellozzo F, Reusser DE, Kropp JP (2018) Climate change mitigation potential of community-based initiatives in Europe. Reg Environ Chang. https://doi.org/10.1007/ s10113-018-1428-1

Luederitz C, Schapke N, Wiek A, Lang DJ, Bergmann M, Bos JJ, Burch S, Davies A, Evans J, Konig A, Farrelly MA, Forrest N, Frantzeskaki N, Gibson RB, Kay B, Loorbach D, McCormick K, Parodi O, Rauschmayer F, Schneidewind U, Stauffacher M, Stelzer F, Rencher G, Venjakob J, Vergragt PJ, von Wehrden H, Westley FR (2017) Learning through evaluation. A tentative evaluative scheme for sustainability transition experiments. J Clean Prod 169:61-76. https://doi.org/10.1016/j.jclepro.2016.09.005

Makard J, Raven R, Truffer B (2012) Sustainability transitions: an emerging field of research and its prospects. Res Policy 41:955-967. https://doi.org/10.1016/j.respol.2012.02.013 
Martellozzo F, Landholm DM, Holsten A (2019) Upscaling from the grassroots: potential aggregate carbon reduction from communitybased initiatives in Europe. Reg Environ Chang. https://doi.org/10. 1007/s10113-019-01469-9

Mattijssen T, Buijs A, Elands B, Arts B (2018) The 'green' and 'self' in green self-governance - a study of 264 green space initiatives by citizens. J Environ Policy Plan 20:96-113. https://doi.org/10.1080/ 1523908X.2017.1322945

Middlemiss M (2011) The effects of community-based action for sustainability on participants' lifestyles. Local Environ 16:265-280. https:// doi.org/10.1080/13549839.2011.566850

Middlemiss L, Parrish B (2010) Building capacity for lowcarbon communities: the role of grassroots initiatives. Energy Policy 38:75597566. https://doi.org/10.1016/j.enpol.2009.07.003

Revell P, Henderson C (2018) Operationalising a framework for understanding community resilience in Europe. Reg Environ Chang. https://doi.org/10.1007/s10113-018-1390-y

Schapke N, Omann I, Wittmayer J, Van Steenbergen F, Mock M (2017) Linking transitions to sustainability: a study of the societal effects of transition management. Sustainability 9:1-36. https://doi.org/10. 3390/su9050737

Sengers F, Wieczorek AJ, Raven R (2016) Experimenting for sustainability transitions: a systematic literature review. Technol Forecast Soc Chang. https://doi.org/10.1016/j.techfore.2016.08.031

Seyfang G, Longhurst N (2016) What influences the diffusion of grassroots innovations for sustainability? Investigating community currency niches. Tech Anal Strat Manag 28:1-23. https://doi.org/10. 1080/09537325.2015.1063603
Seyfang G, Smith A (2007) Grassroots innovations for sustainable development: towards a new research and policy agenda. Environmental Politics 164:584-603. https://doi.org/10.1080/09644010701419121

Seyfang G, Park JJ, Smith A (2013) A thousand flowers blooming? An examination of community energy in the UK. Energy Policy 61: 977-989. https://doi.org/10.1016/j.enpol.2013.06.030

Seyfang G, Hielscher S, Hargreaves T, Martiskainen M, Smith A (2014) A grassroots sustainable energy niche? Reflections on community energy in the UK. Environ Innov Soc Trans 13:21-44. https://doi. org/10.1016/j.eist.2014.04.004

Shove E (2010) Beyond the ABC: climate change policy and theories of social change. Environ Plan A 42:1273-1285. https://doi.org/10. 1068/a42282

Smith A, Seyfang G (2013) Constructing grassroots innovations for sustainability. Glob Environ Chang 23:827-829. https://doi.org/10. 1016/j.gloenvcha.2013.07.003

Tikkanen J, Haara A, Dinnie L, Reusser D, Hujala T, Kajanus M, Kangas J, Kurttila M, Leskinen P (2019) Stochastic cognitive mapping to build common ground for selecting cases in research projects. Reg Environ Chang. https://doi.org/10.1007/s10113-019-01470-2

Publisher's note Springer Nature remains neutral with regard to jurisdictional claims in published maps and institutional affiliations. 